\title{
Caniene cutane mastceltumoren
}

\author{
Canine cutaneous mast cell tumors
}

\section{Van Eetvelde, K. Chiers, L. Van Brantegem}

Vakgroep Pathologie, Bacteriologie en Pluimveeziekten, Faculteit Diergeneeskunde Universiteit Gent, Salisburylaan 133, B-9820 Merelbeke, België

Veterinaire.pathologie@Ugent.be

\section{AMENVATTING}

Caniene cutane mastceltumoren (cMCT) zijn een vaak voorkomende neoplasie in de eerstelijnspraktijk. In 96\% van de gevallen kunnen cMCT worden gediagnosticeerd via cytologie. Het stellen van een prognose is echter geen evidentie omwille van hun variabel biologisch karakter. Aan de hand van verschillende factoren, zoals tumorlocatie, de aanwezigheid van systemische klachten en metastasen, histologische en cytologische gradering, proliferatiemerkers, KIT-lokalisatiepatroon, KIT-mutatie en de tumorvrije randen, wordt de prognose ingeschat. De gekozen behandeling is gebaseerd op het resultaat van deze prognostische factoren, het klinisch stadium en de lokalisatie van de tumor. Mogelijke behandelingen zijn chirurgie, radiotherapie, chemotherapie, elektrochemotherapie, tyrosine-kinasereceptorinhibitor, cryotherapie en intraregionale behandeling met gedeïonizeerd water.

\section{ABSTRACT}

Canine cutaneous mast cell tumors (cMCT) are a commonly encountered neoplasia in small animal practice. Ninety-six percent of the cMCT can be diagnosed with cytology. Because of the variating biological character, it's difficult to establish a prognosis. Therefore, the prognosis is assessed with multiple prognostic factors: tumor location, systemic complaints, metastases, histological and cytological grading, proliferation markers, KIT-staining pattern, KIT-mutation and tumor free margins. The treatment of choice is based upon the results of these prognostic factors, the clinical stage and the tumor location. Possible treatments include surgery, radiotherapy, chemotherapy, electrochemotherapy, tyrosine kinase inhibitors, cryotherapy and intraregional therapy with deionized water.

\section{INLEIDING}

Normale mastcellen zijn voornamelijk gelokaliseerd in de huid, de longen, de lever en de maag (O'Keefe et al., 1990) en spelen een belangrijke rol in de verdedigingsmechanismen van het lichaam (Misdorp, 2004). Tumoraal ontaarde mastcellen vormen de zogenaamde mastceltumoren (MCT). Mastceltumoren worden ingedeeld volgens hun lokalisatie. De cutane MCT (cMCT) omvatten 6-21\% van de caniene huidtumoren (Blackwood et al., 2012), en komen vaak voor proximaal ter hoogte van de achterste ledematen, de perineale en preputiale regio (Misdorp, 2004) en op de romp (Raskin, 2010). Deze worden verder ingedeeld in de dermale en subcutane MCT omwille van hun verschillend biologisch karakter (Kiupel, 2017). Daarnaast zijn er de extracutane MCT die vooral ter hoogte van de conjunctiva, de speekselklier, de nasopharynx, de larynx, de mondholte, het gastro-intestinale stelsel, de urethra, het ruggenmerg (Dobson et al., 2007) en de ureter (Steffey et al., 2004) worden waargenomen. Bij de viscerale vorm (ook wel de systemische of gedissemineerde mastocytose genoemd) worden neoplastische mastcellen vooral in de abdominale lymfeknopen, de lever, de milt en het beenmerg waargenomen (O'Keefe et al., 1987). Deze vorm komt hoofdzakelijk voor in aanwezigheid van een primaire agressieve cMCT (O'Keefe et al.,1987). Tot slot is er mastcelleukemie die ontstaat in het beenmerg en gekenmerkt wordt door een significante aanwezigheid van mastcellen in het perifere bloed en het beenmerg (Marconato et al., 2008; De Bosschere et al., 2008). De extracutane en leukemievarianten worden vrij zeldzaam gezien (Marconato et al., 2008).

\section{SIGNALEMENT}

De gemiddelde leeftijd waarop de diagnose van cMCT gesteld wordt, is negen jaar (Patnaik et al., 1984; Blackwood et al., 2012). Toch komt de tumor uitzonderlijk voor bij honden jonger dan één jaar 
(Teske et al., 2007). Davis et al. (1992) beschreven een jackrussellterriërpup van drie weken met multipele cMCT. Op de leeftijd van 35 weken waren alle nodulen volledig geregresseerd. Deze spontane regressie indiceert eerder hyperplasie of dysplasie van mastcellen dan een neoplastisch proces (Davis et al., 1992; Teske et al., 2007; London et al., 2013). Er is geen aanwijzing voor geslachtspredispositie (Patnaik et al., 1984). Mastceltumoren worden frequent gediagnosticeerd bij boxers, bostonterriërs, bulterriërs, bulmastiffs, cockerspaniëls, staffordshireterriërs, foxterriërs, Engelse buldogs, teckels, labrador-retrievers, golden retrievers, beagles, mopshonden, schnauzers, sharpeis, Rhodesian ridgebacks, weimaraners en Australian cattle dogs (Patnaik et al., 1984). Deze raspredispositie toont mogelijk een genetische invloed aan, op zowel de vatbaarheid als het biologisch karakter van de tumor (Zemke et al., 2002).

\section{KLINISCHE BEVINDINGEN}

Het biologisch karakter van cMCT is zeer uiteenlopend en kan gaan van goedaardige, solitaire tumoren naar fataal verlopende maligne tumoren die metastaseren (Misdorp et al., 2004; Blackwood et al., 2012). Goed gedifferentieerde tumoren zijn meestal alleenstaande, kleine, traaggroeiende nodulen, waarbij de bovenliggende huid een normale beharing of alopecie vertoont; in tegenstelling tot de weinig gedifferentieerde cMCT die snel groeien en vaak groot en geülcereerd zijn. Het omgevend weefsel kan oedemateus zijn en satellietnodulen bevatten. Subcutane MCT worden regelmatig verkeerdelijk gediagnosticeerd als lipoom door hun gelijkaardig uitzicht en consistentie bij palpatie (Blackwood et al., 2012; London et al., 2013). Door degranulatie van mastcellen worden histamine, heparine en vasoactieve substanties vrijgesteld die aanleiding geven tot lokale en systemische symptomen (Mullins et al., 2006) die bij 50\% van de

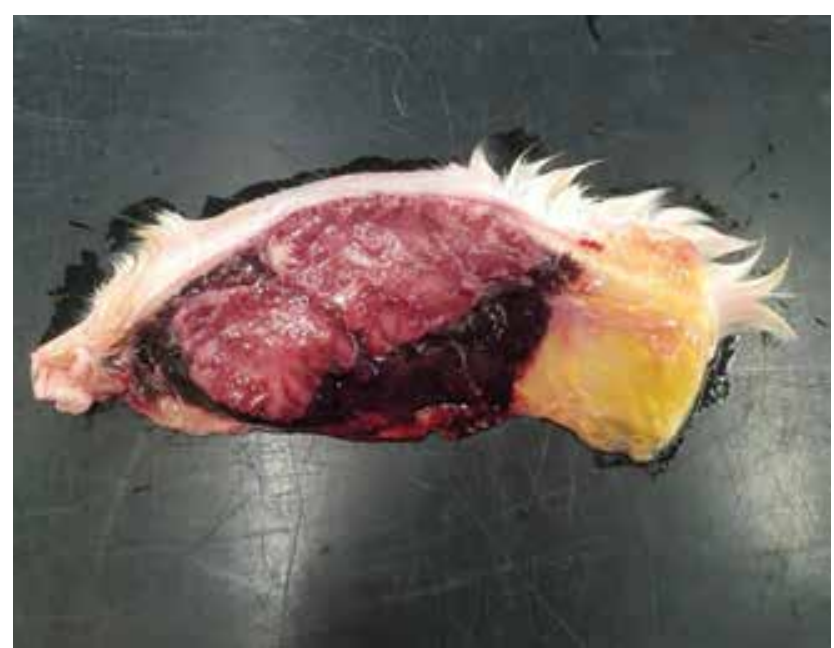

Figuur 1. Dwarsdoorsnede van een cutane mastceltumor $(20 \times 24 \mathrm{~cm})$. Bemerk de uitgebreide bloedingen en oedeem. honden met MCT voorkomen (Teske et al., 2007). Ter hoogte van de huid kunnen er lokale vasodilatatie, oedeem, bloedingen, jeuk en ulceraties waargenomen worden (Blackwood et al., 2012) (Figuur 1). Soms kan de tumor in omvang verkleinen en/of vergroten (Londone et al., 2013). Mogelijk kunnen een lokaal vertraagde wondheling (Dobson et al., 2007) en coagulatiestoornissen met lokale bloedingen tot gevolg optreden (O'Keefe et al., 1987). Systemisch worden gastro-intestinale klachten gezien, zoals braken, anorexie, abdominale pijn, hematochezie en melena. (Dobson et al., 2007; Blackwood et al., 2012; London et al., 2013; Kiupel, 2017). Deze symptomen treden secundair op door de aanwezigheid van gastroduodenale erosies- en/of ulceraties die ontstaan na vrijstelling van histamine dat bindt op de H2-receptor van de pariëtale cellen, met verhoogde $\mathrm{HCl}$-productie tot gevolg (Kiupel, 2017). Honden die een cMCT hebben, kunnen sterven aan deze secundaire gevolgen of aan een anafylactische shock door massale mastceldegranulatie (Misdorp, 2004).

\section{DIAGNOSE}

\section{Cytologie}

In $96 \%$ van de gevallen kan de diagnose van cMCT worden gesteld via een fijnenaaldaspiraat (FNA) (Baker-Gab et al., 2003). Na het aankleuren met de gemodificeerde romanowsky-kleuring (diff quick of hemacolor) worden individuele, kleine tot middelgrote, ronde cellen met intracytoplasmatisch, metachromatische granulen gezien (Figuur 2). De mastcellen kunnen soms zodanig veel granulen bevatten dat de kern niet meer waarneembaar is. Andere cMCT kunnen dan weer tumorale mastcellen hebben die heel weinig granulen bevatten (Kiupel, 2017). Naast mastcellen kunnen nog een variabele hoeveelheid eosinofielen en/ of plompe spoelvormige cellen (vermoedelijk fibro-

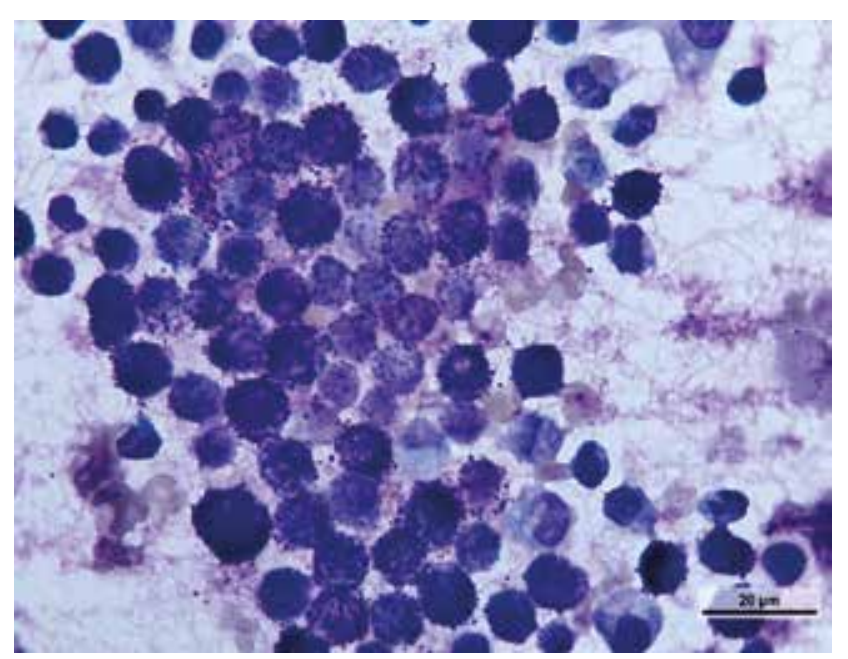

Figuur 2. Cytologie gekleurd met diff Quick. Mastcellen met multipele metachromatische granulen. 


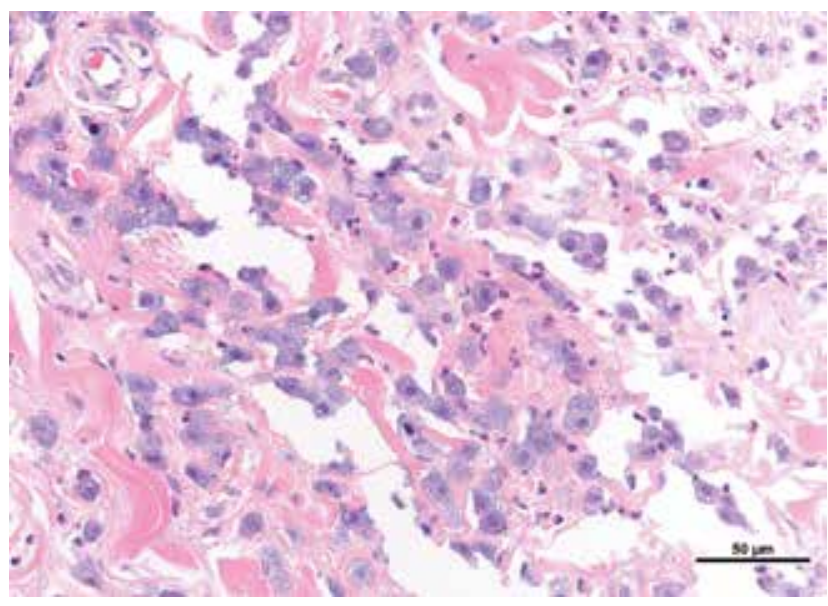

Figuur 3. Histologische afbeelding. HE-kleuring, mastcellen met lichtgrijs tot blauwe granulen en er zijn enkele eosinofielen aanwezig.

blasten) aangetroffen worden (Welle et al., 2008). Cytologisch kunnen bloeding, vasculaire necrose, oedeem en collagenolyse opgemerkt worden als gevolg van mastceldegranulatie (Raskin, 2010).

\section{Histologie}

Op histopathologisch onderzoek van een caniene cMCT ziet men op hematoxyline-eosinekleuring (HE) een niet-omkapselde, meestal infiltratieve matige tot sterke, celrijke massa bij slecht gedifferentieerde cMCT , en bij goed gedifferentieerde cMCT een nietomkapselde, goed afgelijnde, matige tot sterke, celrijke massa (Kiupel, 2017) (Figuur 3). De tumorale cellen zijn geordend in strengen of losse sheets. De middelmatige tot grote, ronde tot polygonale cellen hebben duidelijke celranden, een grote centrale kern en hebben een matige tot grote hoeveelheid licht eosinofiel cytoplasma met intracytoplasmatische lichtgrijze tot blauwe granulen. Deze granulen kleuren paars aan wanneer een metachromatische kleuring zoals giemsakleuring of toluïdineblauwkleuring worden toegepast (Kiupel, 2017) (Figuur 4). Het aantal mitosefiguren varieert tussen een goed gedifferentieerde en een slecht gedifferentieerde cMCT. Slecht gedifferentieerde cMCT hebben vaak ook meerkernige cellen, bizarre kernen, karyomegalie en een duidelijke anisokaryose (Kiupel et al., 2011). Een variabele hoeveelheid eosinofielen is verspreid tussen de neoplastische cellen (Welle et al., 2008) en kan soms het predominante celtype zijn (Kiupel, 2017). Collagenolyse, sclerose, oedeem, necrose en secundaire lymfocytaire inflammatie worden frequent opgemerkt bij cMCT (Kiupel, 2017).

\section{PROGNOSE}

Er wordt veel onderzoek uitgevoerd naar de prognose van cMCT. Enerzijds is dit gebaseerd op de anatomische lokalisatie en symptomen, anderzijds wordt

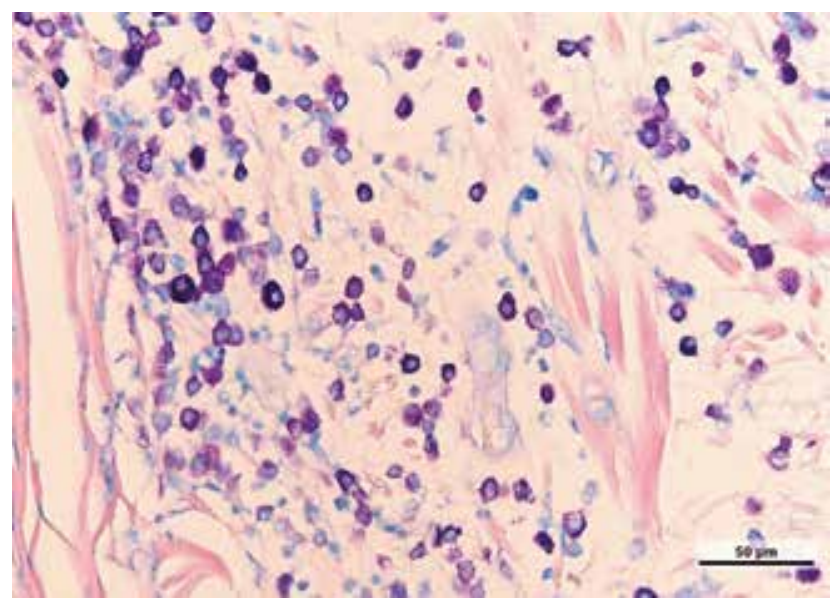

Figuur 4. Histologische afbeelding. Giemsakleuring, mastcellen waarbij de granulen metachromatisch of donker paars aankleuren.

gebruik gemaakt van histologische maligniteitskenmerken en (immuno)histochemische merkers. Deze laatste worden vooral aangewend voor dermale MCT.

\section{Tumorlocatie}

De tumorlocatie wordt aanzien als een mogelijke prognostische indicator (Mullins et al., 2006). Mastceltumoren ter hoogte van de preputiale en inguinale regio, het nagelbed, mucocutane lokalisaties (London et al., 2013), de viscera, het beenmerg (O'Keefe et al., 1987) en de snuit worden geassocieerd met een agressief biologisch karakter (Gieger et al., 2003). De subcutane MCT hebben merendeels een gunstige prognose (Thompson et al., 2011).

\section{Systemische klachten}

De aanwezigheid van systemische klachten die vaak geassocieerd zijn met de viscerale vorm leiden tot een slechtere prognose (O'Keefe et al., 1990; Mullins et al. 2006).

\section{Metastasen}

Om een volledig beeld te krijgen van de prognose dient er een FNA van de regionale lymfeknoop te worden genomen, zelfs indien deze niet vergroot is (Blackwood et al., 2012). De aanwezigheid van metastasen in de regionale lymfeknoop zorgt voor een gereserveerde prognose (Murphy et al., 2006). Interpretatie van de cytologie is niet eenvoudig omdat mastcellen normaal voorkomen in lymfeknopen (Dobson et al., 2007). Men spreekt over metastase indien 3\% van de celpopulatie bestaat uit mastcellen (Dobson et al., 2007) en wanneer de mastcellen in clusters of aggregaten aanwezig zijn (Dobson et al., 2007). Stefanello et al. (2009) raden aan om standaard een echografisch begeleidde FNA van milt en lever uit te voeren, ook wanneer beide organen een normaal uitzicht vertonen. Hierover bestaat enige discussie aangezien 
Tabel 1. Klassering van caniene mastceltumoren volgens Patnaik en de daarbijhorende prognose (Patnaik et al., 1984).

\begin{tabular}{|c|c|c|}
\hline Graad & $\begin{array}{l}\text { Prognose } \\
\text { na excisie }\end{array}$ & Histologische kenmerken \\
\hline $\begin{array}{l}\text { I } \\
\text { Laaggradig of } \\
\text { goed gedifferentieerd }\end{array}$ & $\begin{array}{l}83 \% \text { overleeft } \\
>4 \text { jaar }\end{array}$ & $\begin{array}{l}\text { Monomorf ronde cellen, veel cytoplasma met duidelijke grenzen } \\
\text { Middelgrote intracytoplasmatische granulen } \\
\text { Mitosefiguren zijn afwezig } \\
\text { De lokalisatie van de tumor beperkt zich tot de dermis en de } \\
\text { interfolliculaire ruimtes } \\
\text { Minimale hoeveelheid oedeem en necrose }\end{array}$ \\
\hline $\begin{array}{l}\text { II } \\
\text { Intermediaire graad }\end{array}$ & $\begin{array}{l}44 \% \text { overleeft } \\
>4 \text { jaar }\end{array}$ & $\begin{array}{l}\text { Pleiomorfe cellen die rond tot ovaal kunnen zijn } \\
\text { Uitgesproken cytoplasma } \\
\text { Fijne intracytoplasmatische granulen, sommige hebben een } \\
\text { minder uitgesproken cytoplasma met hyperchromatische } \\
\text { en grote granulen } \\
\text { Mitosefiguren zijn zeldzaam ( } 0-2 \text { per "high power field"), } \\
\text { Zones van diffuus oedeem en necrose } \\
\text { Komen voor ter hoogte van de dermis en subcutis }\end{array}$ \\
\hline $\begin{array}{l}\text { III } \\
\text { Hooggradig of } \\
\text { slecht gedifferentieerd }\end{array}$ & $\begin{array}{l}10 \% \text { overleeft } \\
>1 \text { jaar }\end{array}$ & $\begin{array}{l}\text { Pleiomorfe cellen van gemiddelde grootte die rond, } \\
\text { ovaalvormig, spoelvormig kunnen zijn } \\
\text { Onduidelijk cytoplasma met fijne intracytoplasmatische } \\
\text { granulen of onduidelijke granulen } \\
\text { Aanwezigheid van tweekernige cellen, reuzencellen, mitosefiguren } \\
\text { worden regelmatig gezien (3-6 per "high power field") } \\
\text { Oedeem, bloeding en necrose worden veel gezien } \\
\text { Gelokaliseerd in de subcutis en diepere weefsels }\end{array}$ \\
\hline
\end{tabular}

mastcellen gangbaar voorkomen in de gezonde lever en milt en in aantal kunnen stijgen bij verschillende ziekteprocessen (Finora et al., 2006).

\section{Histologische gradering}

Histologische gradering is van belang voor het bepalen van het biologisch gedrag van cMCT, voor de prognose en het kiezen van de meest accurate therapeutische behandeling (Patnaik et al., 1984). Er bestaan verschillende graderingssystemen. Zowel het systeem van Bostock als dat van Patnaik classificeren de cMCT in drie graden die gecorreleerd zijn met de klinische uitkomst (Patnaik et al., 1984; Blackwood et al., 2012) (Tabel 1). Graad I (GI) of laaggradige of goed gedifferentieerde cMCT (patnaiksysteem) draagt een zeer goede prognose terwijl graad III- (GIII) of hooggradige of slecht gedifferentieerde cMCT (patnaiksysteem) geassocieerd is met een gereserveerde tot slechte uitkomst (Murphy et al., 2004). Het biologisch gedrag van graad II- (GII) of intermediaire cMCT (patnaiksysteem) is moeilijker te voorspellen, waardoor er geen duidelijkheid is over de prognose (Sabattini et al., 2015). Nadelig aan het patnaiksysteem is dat er heel wat variatie tussen verschillende pathologen of interobserver-variabiliteit wordt gezien bij graad I en II (Kiupel et al., 2011). In een studie van Kiupel et al. (2011) werd vastgesteld dat voor deze twee graden slechts $63 \%$ van de pathologen tot dezelfde conclusie kwam. Daarnaast werd 53\% van de cMCT als graad II beschouwd die zowel een goedaardig als kwaadaardig gedrag kunnen vertonen (Kiupel et al., 2011).

Om die reden stelden Kiupel et al. (2011) een nieuw graderingssysteem voor. In dat systeem worden de tumoren gedifferentieerd als laag-(LG) of hoog(HG) gradige cMCT (twee-tiersysteem) (Tabel 2). Deze indeling is gebaseerd op het aantal mitosefiguren in combinatie met karyomegalie, meerkernigheid en bizarre nuclei (Kiupel et al., 2011).

In tegenstelling tot het patnaikgraderingssysteem kwamen de pathologen in $97 \%$ van de gevallen tot hetzelfde besluit, wat dus wijst op een veel lagere inter-observervariabiliteit (Kiupel et al., 2011). Hooggradige $\mathrm{cMCT}$ hebben een groot risico om agressief te evolueren. Zowel de laaggradige tumoren (twee-tiersysteem) als de intermediaire graad (patnaiksysteem) dienen verder te worden beoordeeld met behulp van andere prognostische merkers om hun biologisch gedrag te kunnen inschatten (Kiupel et al., 2011).

Het patnaiksysteem zou volgens Vascellari et al. (2012) sensitiever zijn dan het twee-tiersysteem van Kiupel dat meer specificiteit heeft voor het detecteren van agressieve cMCT. Beide systemen zouden elkaar kunnen aanvullen voor het stellen van een prognose en het bepalen van het biologisch gedrag van cMCT 
Tabel 2. Klassering van caniene mastceltumoren volgens het kiupelsysteem.

\begin{tabular}{|c|c|c|}
\hline Hooggradig & $\begin{array}{l}\text { Criteria } \\
\text { (minstens één) } \\
\text { Prognose }\end{array}$ & $\begin{array}{l}\geq 7 \text { mitosen / } 10 \text { "high power field" } \\
\geq \text { meerkernige cellen }(\geq 3 \text { kernen per cel) / } 10 \text { "high power field" } \\
\geq 3 \text { bizarre kernen / } 10 \text { "high power field" } \\
\text { Karyomegalie }(\geq 10 \% \text { cellen: kernen met dubbele diameter } \\
\text { Snellere metastasering } \\
\text { Mediane overlevingstijd }<4 \text { maanden }\end{array}$ \\
\hline Laaggradig & $\begin{array}{l}\text { Criteria } \\
\text { Prognose }\end{array}$ & $\begin{array}{l}\text { Geen enkel van hoger genoemde criteria } \\
\text { Langere duur tot metastasering } \\
\text { Mediane overlevingstijd }>2 \text { jaar }\end{array}$ \\
\hline
\end{tabular}

Tabel 3. Klassering van caniene mastceltumoren volgens het gecombineerde patnaik- en kiupelsysteem (Berlato et al., 2017, pending publishing).

\begin{tabular}{lllll}
\hline Graad & Prognose & $\begin{array}{l}\text { Regionale } \\
\text { metastase }\end{array}$ & $\begin{array}{l}\text { Metastase } \\
\text { op afstand }\end{array}$ & Referenties \\
\hline GI/LG & Uitstekend & $6 \%$ & $2 \%$ & $\begin{array}{l}\text { Patnaik et al., 1984; Stefanello et al., } \\
\text { 2009; Kiupel et al., 2011 }\end{array}$ \\
GII/LG & $\begin{array}{l}\text { Goed, 6\% sterft aan MCT- } \\
\text { gerelateerde aandoening }\end{array}$ & $16 \%$ & $2 \%$ & $\begin{array}{l}\text { Stefanello et al., 2009; } \\
\text { Sabattini et al., 2015 }\end{array}$ \\
GIII/HG & $\begin{array}{l}\text { Gereserveerd, 50\% sterft aan } \\
\text { MCT-gerelateerde aandoening }\end{array}$ & $15 \%$ & $2 \%$ & $\begin{array}{l}\text { Stefanello et al., 2009; } \\
\text { Sabattini et al., 2015 }\end{array}$ \\
GIII/HG & $\begin{array}{l}\text { Gereserveerd tot slecht, 67-75\% } \\
\text { sterft aan MCT-gerelateerde aandoening }\end{array}$ & $46-49 \%$ & $21 \%$ & $\begin{array}{l}\text { Murphy et al., 2004; } \\
\text { Stefanello et al., 2009; } \\
\text { Sabattini et al., 2015 }\end{array}$ \\
\hline
\end{tabular}

(Sabattini et al., 2015). Indien beide systemen samen gebruikt worden, kan men de cMCT indelen in vier categorieën (Berlato et al., 2017, pending publishing) (Tabel 3).

Het verschil in overlevingstijd tussen GII/LG en GII/HG ligt eerder aan het lokaal heroptreden van MCT dan aan de aanwezigheid van metastasen (Berlato et al., 2017, pending publishing).

Histologische gradering dient steeds in combinatie met andere prognostische factoren, zoals de proliferatiemerkers, de tumorlocatie, de aanwezigheid van metastasen, KIT-mutatie en KIT-lokalisatiepatroon beoordeeld te worden. Een histologisch goedaardig lijkende tumor kan zich nog steeds klinisch agressief manifesteren (Berlato et al., 2017, pending publishing).

\section{Cytologische gradlering}

Camus et al. (2016) werkten een algoritme uit voor het graderen van cMCT via cytologie. Hiervoor baseerden ze zich op het twee-tiersysteem, waarbij de cMCT worden ingedeeld in hoog- en laaggradige cMCT (Camus et al., 2016) (Figuur 5). Cytologische gradering kan nuttig zijn voor het inschatten van de prognose vóór een chirurgische excisie wordt uitge-

Weinig intracytoplasmatische granules

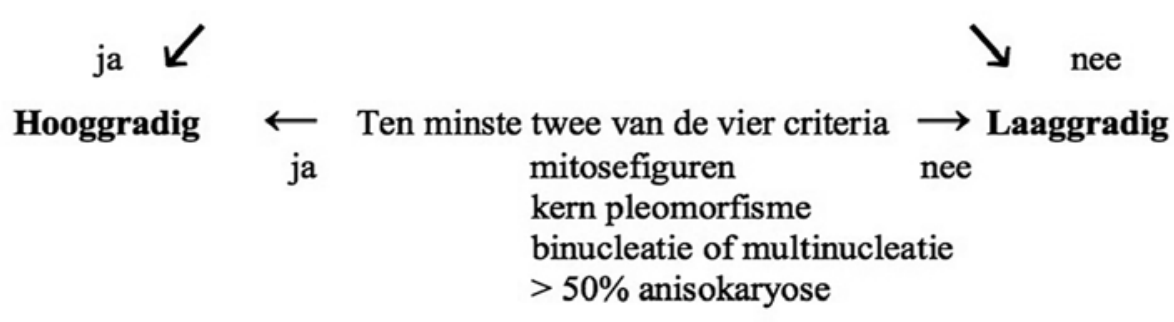

Figuur 5. Algoritme voor cytologische gradering van een cMCT (Camus et al., 2016). 
voerd (Camus et al., 2016). De nadelen van cytologische gradering zijn dat er meer valspositief hooggradige tumoren worden gediagnosticeerd dan bij histologische gradering (Camus et al., 2016) en dat er geen onderscheid kan gemaakt worden tussen dermale en subcutane MCT (Berlato et al., 2017, pending publishing).

\section{Proliferatiemerkers}

Proliferatiemerkers zijn van groot belang in het bepalen van de prognose en de therapierespons en zijn in zekere mate minder subjectief dan het histologisch graderingsysteem van Patnaik of Boystock (Blackwood et al., 2012; Vascellari et al., 2012). Het biologisch gedrag van zowel de laaggradige tumoren (twee-tiersysteem) als de intermediaire graad (patnaiksysteem) dienen ingeschat te worden aan de hand van deze proliferatiemerkers (Kiupel et al. 2011). De mitose-index en de immunohistochemische proliferatiemerkerkleuring Ki67 hebben de belangrijkste prognostische waarde bij cMCT (Vascellari et al., 2012). Indien beide merkers een tegenstrijdig beeld geven, kan de practicus op basis van andere prognostische factoren zelf besluiten welke behandelingsmethode zal toegepast worden.

\section{Mitose-index (MI)}

De mitose-index is de meest gebruikte methode om celproliferatie in te schatten en kan afgelezen worden op een gewone HE-kleuring (Romansik et al., 2007; Thompson et al., 2011; Kiupel et al., 2011). De MI wordt bepaald door het aantal mitosen per 10 "high power fields" (Blackwood et al., 2012). Romansik et al. (2007) toonden aan dat honden met een cMCT met $\mathrm{MI}>5$ een gemiddelde overlevingstijd van twee maanden hebben en honden met een cMCT met MI $<5$ gemiddeld nog zeventig maanden leven. De MI kan dus een goede inschatting geven van de gemiddelde overlevingstijd (Romansik et al., 2007). De intracytoplasmatische granulen kunnen soms interfere- ren met het correct tellen van het aantal mitosefiguren (Kiupel, 2017).

\section{Ki67}

Ki67 is een nucleaire proteïne dat aanwezig is in alle actieve fasen van de celcylus (London et al., 2013) en kan aangetoond worden met een immunohistochemische kleuring (Blackwood et al., 2012) (Figuur 6). Deze merker is van belang voor het bepalen van de overlevingstijd van honden met cMCT die als graad II zijn ingedeeld (Scase et al., 2006). Scase et al. (2006) toonden aan dat indien meer dan 1,8\% van de cellen positief aankleurt, de verwachte overlevingstermijn lager ligt dan wanneer minder dan $1,8 \%$ positief aankleurt (Tabel 4).

\section{"Argyrophilic nucleolar organizer region" proteïnen (AgNOR)}

AgNOR is een merker voor de proliferatiesnelheid (London et al., 2013). Het bindt zilvermoleculen en kan gevisualiseerd worden via een op zilver gebaseerde histochemische kleuring (Blackwood et al., 2012). Een gecombineerde AgNOR x Ki67-score kan het risico op herval bij cMCT, waarbij geen volledige chirurgische excisie mogelijk was, inschatten (Smith et al., 2015). Ondanks hun merendeels gunstige prognose kunnen subcutane MCT in 5-15\% een agressief karakter bezitten dat door de gecombineerde AgNOR x Ki67-score kan aangetoond worden (Thompson et al., 2011).

\section{KIT-mutatie}

Het c-kit proto-oncogen codeert het KIT-proteïne dat een tyrosine-kinasereceptor is. De tyrosine-kinasereceptoren bevinden zich op het celoppervlak en door triggering van een ligand wordt cellulaire activatie verkregen met cellulaire proliferatie, differentiatie en overleving van de mastcel tot gevolg (Dank, 2016). Voor verschillende caniene cMCT is er een mutatie

Tabel 4. Ki67-geassocieerde overlevingstijd (Scase et al., 2006).

\begin{tabular}{|c|c|c|c|}
\hline Ki67 & Overlevingskans & $<1,8 \%$ Positieve cellen & $>1,8 \%$ Positieve cellen \\
\hline & 1 jaar & $92 \%$ & $43 \%$ \\
\hline & 2 jaar & $86 \%$ & $21 \%$ \\
\hline & 3 jaar & $77 \%$ & $21 \%$ \\
\hline
\end{tabular}

Tabel 5. KIT-lokalisatiepatroon bij tumorale caniene mastcellen, geassocieerd met recidief en sterfte (Kiupel et al., 2004).

\begin{tabular}{|lcc}
\hline Patroon bij 10\% van de neoplastische cellen & Recidief & Sterfte \\
\hline Perimembranair of KIT-lokalisatiepatroon I & $2,4 \%$ & $2,4 \%$ \\
Gestipt cytoplasmatisch of KIT-lokalisatiepatroon II & $14 \%$ & $25,6 \%$ \\
Diffuus cytoplasmatisch of KIT-lokalisatiepatroon III & $23 \%$ & $38,5 \%$ \\
\hline
\end{tabular}




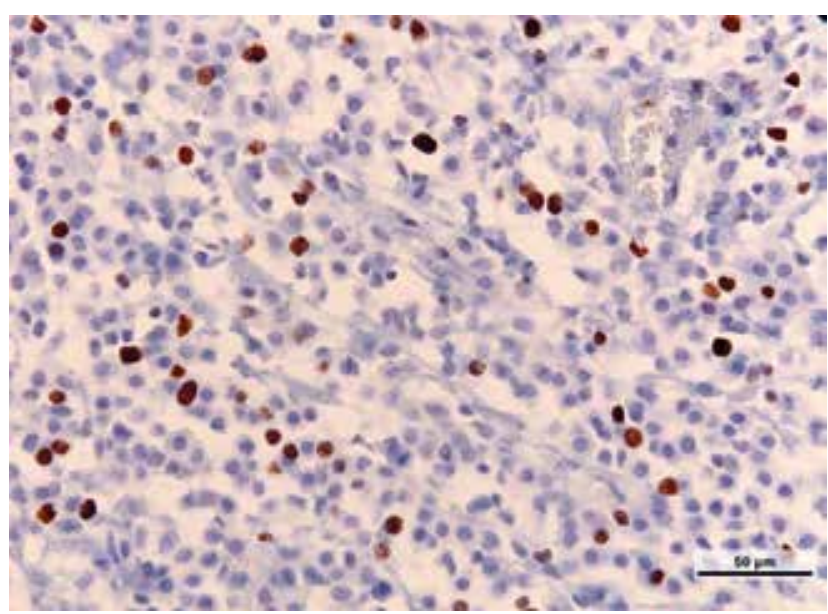

Figuur 6. Histologische afbeelding. Immunohistochemische kleuring met Ki67. De achtergrond kleurt grijsblauw aan. Positieve Ki67-cellen kleuren bruin aan.

geïndentificeerd in de juxtamembraneuze coderingsregio van het c-kit proto-oncogen die opgespoord wordt met behulp van "polymerase chain reaction" (PCR) (Zemke et al., 2002). De mutatie geeft aanleiding tot activatie van de tyrosine-kinasereceptor zonder aanwezigheid van ligandbinding (Zemke et al., 2002). Deze mutatie wordt gezien in $30 \%$ van de gevallen bij intermediaire en hooggradige MCT en is geassocieerd met een slechte prognose (Zemke et al., 2002).

\section{KIT-lokalisatiepatroon}

Er bestaat een correlatie tussen de expressie van de KIT-receptor en de differentiatie van de cMCT. Goed gedifferentieerde cMCT vertonen vaak een zwakke expressie van KIT. Slecht gedifferentieerde cMCT bezitten regelmatig een hoge KIT-expressie (Reguera et al., 2000).

Bij normale mastcellen en bij sommige neoplastische mastcellen bevindt KIT zich hoofdzakelijk op de celmembraan. Bij de meeste neoplastische mastcellen daarentegen worden ze voornamelijk gevonden in het cytoplasma (Reguera et al., 2000). Kiupel et al. (2004) toonden het verband aan tussen de aanwezigheid van intracytoplasmatische KIT-expressie en een gestegen kans op herval en een gedaalde overlevingstijd (Kiupel et al., 2004) (Tabel 5). Dezelfde associatie kan niet gemaakt worden bij neoplastische mastcellen met een perimembraneuze KIT-expressie (Kiupel et al., 2004) (Figuur 7).

\section{Evaluatie van tumorvrije randen}

Vele laaggradige cMCT zijn goed omlijnd maar niet omkapseld, waarbij de tumorgrenzen gemakkelijk te identificeren zijn. Dit in tegenstelling tot de hooggradige cMCT, waarbij neoplastische cellen vaak het omgevend weefsel invaderen (Kiupel, 2017). Daarnaast bevatten vele cMCT een reactieve halo bestaande uit oedeem, inflammatoire cellen en reactieve

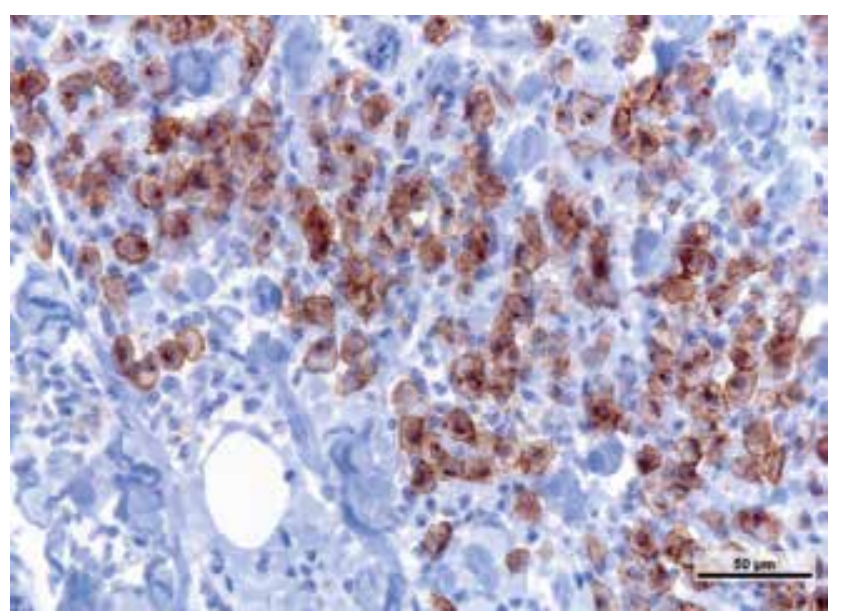

Figuur 7. KIT-lokalisatiepatroon met perimembraneuze KIT-expressie.

stromale cellen, wat de differentiatie tussen neoplastische en normale mastcellen moeilijk maakt (Kiupel, 2017). Er wordt ervan uitgegaan dat de mastcellen gelegen in clusters, neoplastische cellen zijn en de alleenstaande, goed gedifferentieerde mastcellen tot de inflammatoire mastcellen behoren (Kiupel, 2017). Ondanks het nemen van chirurgisch wijde grenzen en de aanwezigheid van tumorvrije randen op histopathologisch onderzoek hervalt $36 \%$ van de hooggradige (kiupelsysteem) of graad III- (patnaiksysteem) cMCT lokaal (Donnelly et al., 2015). Bij laaggradige (kiupelsysteem) en graad II- (patnaiksysteem) cMCT recidiveert 4-21\% lokaal (Murphy et al., 2004; Donnelly et al., 2015).

\section{BEHANDELING}

De gekozen therapie is afhankelijk van prognostische factoren, het klinisch stadium (London et al., 2013) en de lokalisatie (Blackwood et al., 2012). Mogelijke behandelingen zijn chirurgie, radiotherapie, chemotherapie en tyrosine-kinasereceptorinhibitors, elektrochemotherapie, cryotherapie en intraregionale therapie met gedeïonizeerd water.

\section{Chirurgie}

Daar waar de lokalisatie van de cMCT het toelaat, is chirurgie de meest geprefereerde keuze (Blackwood et al. 2012; London et al., 2013). Na chirurgische excisie heeft $80 \%$ van de honden met graad I cMCT een overlevingstijd van meer dan vier jaar. Bij graad II is dit $44 \%$ en bij graad III $6 \%$ (Patnaik et al., 1984). Voor laaggradige (graad I) en intermediaire (graad II) cMCT kleiner dan $4 \mathrm{~cm}$, zou een chirurgische marge van lateraal $2 \mathrm{~cm}$ en 1 fasciaal vlak in de diepte voldoende zijn (Dobson et al., 2007). Voor cMCT groter dan $4 \mathrm{~cm}$ werden deze marges nog niet bestudeerd. Bij hooggradige (graad III) cMCT dient een laterale grens van $3 \mathrm{~cm}$ en een diep faciaal vlak te 


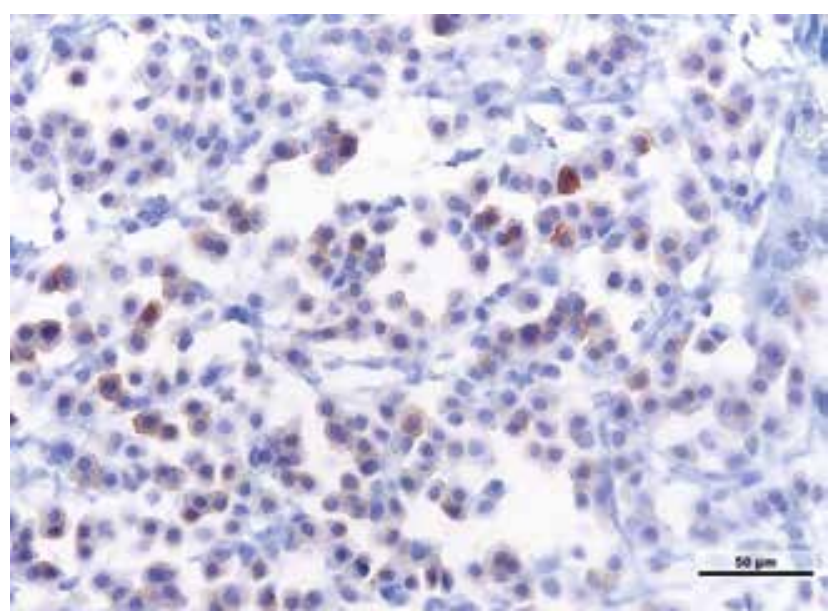

Figuur 8. KIT-lokalisatiepatroon met gestipte cytoplasmatische KIT-expressie.

worden aangehouden (Blackwood et al., 2012). Negentig procent van de laaggradige cMCT en de subcutane MCT kunnen genezen door enkel chirurgische excisie (Thompson et al., 2011; Kiupel et al. 2011). Zoals hoger aangegeven, kunnen laaggradige cMCT zich soms agressief gedragen en is er eventueel bijkomend nood aan andere therapieën na de chirurgische excisie. Om hier een onderscheid te kunnen maken, worden de volgende prognostische merkers gebruikt: Ki67, de combinatie van Ki67 en AgNOR, en het KIT-lokalisatiepatroon (Kiupel, 2017).

Indien geen volledige excisie bereikt is na de eerste operatie, dient een tweede operatie rond het oorspronkelijke operatielitteken te worden uitgevoerd (Blackwood et al., 2012; Dank, 2016). Hierbij moet een marge van $2 \mathrm{~cm}$ aangehouden worden (Blackwood et al., 2012). Er kan ook gekozen worden om de overgebleven neoplastische cellen te behandelen met radiotherapie (Blackwood et al., 2012).

\section{Radiotherapie}

Het behandelen van cMCT enkel met radiotherapie dient vermeden te worden omwille van een verhoogde kans op mastceldegranulatie (LaDue et al., 1998; Blackwood et al., 2012). Daarbij komt dat grote nodulen de neiging hebben om radioresistent te zijn (LaDue et al., 1998). Radiotherapie is echter wel ideaal om bij incomplete excisie als bijkomende behandeling van cMCT toegepast te worden of om lokale of regionale metastasen te behandelen (LaDue et al., 1998; Blackwood et al., 2012).

\section{Chemotherapie}

Chemotherapie kan op drie verschillende manieren worden aangewend (Blackwood et al., 2012; Dank, 2016). Als eerste kan neo-adjuvante chemotherapie toegepast worden om de tumorgrootte te reduceren en om chirurgie mogelijk te maken of complete excisie te bekomen (Blackwood et al., 2012) of ter voorbereiding op radiotherapie (Blackwood et al., 2012). Prednisolone aan een dosis van $1 \mathrm{mg} / \mathrm{kg}$ per dag zorgt

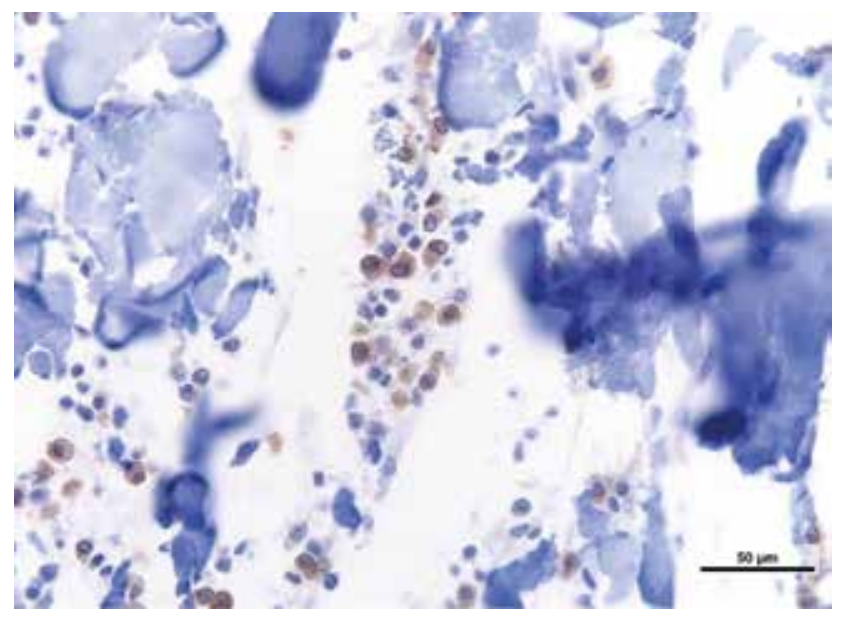

Figuur 9. KIT-lokalisatiepatroon met diffuus cytoplasmatische KIT-expressie.

voor een significante reductie van de tumorgrootte bij ongeveer $70 \%$ van de cMCT (Stanclift et al., 2008).

Een tweede geval waarbij chemotherapie ingezet kan worden, is bij afwezigheid van tumorvrije randen (Blackwood et al., 2012; Dank, 2016). Hoewel radiotherapie hiervoor eigenlijk de eerste keuze is, wordt chemotherapie toegepast in praktijken waar de faciliteiten voor radiotherapie afwezig zijn (Davies et al., 2004). In een studie van Davies et al. (2004) werden twintig honden met cMCT van graad II of III met incomplete excisie behandeld met vinblastine en prednisolone. Twaalf tot vierentwintig maanden na de start van de chemotherapie bleek de kans op herval klein te zijn (Davies et al., 2004).

Indien een hoog risico op metastasen bestaat, zoals het geval is bij hooggradige of graad III- en sommige graad II-tumoren met hoge proliferatieparameters, wordt gebruik gemaakt van systemische chemotherapeutica (Blackwood et al., 2012; Dank, 2016). Deze hebben tot doel om metastasen te voorkomen of te vertragen (Blackwood et al., 2012). De eerstelijnschemotherapeutica bestaan voornamelijk uit een combinatie van vinblastine en prednisolone. Tweedelijns wordt lomustine gebruikt, maar alternerende toediening van vinblastine en lomustine wordt ook vaak toegepast (Blackwood et al., 2012). Het nadeel van deze chemotherapeutica is de neveneffecten. Vinblastine geeft een sterke perivasculaire irritatie, is potentieel myelosuppressief en geeft milde gastro-intestinale klachten (anorexie, diarree, braken) (Blackwood et al., 2012). Lomustine kan voor ernstige beenmergsuppressie zorgen en is eveneens hepatotoxisch (Blackwood et al., 2012).

\section{Prednisone}

McCaw et al. (1994) behandelden 25 honden met prednisone aan een dosis van $1 \mathrm{mg} / \mathrm{kg}$ SID. Van de 25 honden vertoonden er vijf een daling van het tumorvolume (McCaw et al., 1994). Aangezien MCT kleiner of groter kunnen worden, kan de behandelingsrespons van deze studie in vraag gesteld worden (London et al., 2013). 


\section{Tyrosine-kinase-inhibitors}

Tyrosine-kinase-inhibitors zijn in staat om de activiteit van de receptoren te blokkeren door competitieve inhibitie met de ATP-binding. Mastinib (Masivet ${ }^{\circledR}, A B$ Science S.A., Frankrijk) en toceranib fosfaat (Palladia ${ }^{\circledR}$, Zoetis, België) zijn beide geregistreerd voor het gebruik bij honden met cMCT (Blackwood et al., 2012).

Het resultaat van mastinib is meer uitgesproken indien het als eerstekeuzetherapie wordt aangewend, ongeacht de aanwezigheid van een mutatie van KIT of wild type KIT (Hahn et al., 2008). Hierdoor bestaat de mogelijkheid dat mastinib bijkomend via een andere weg de tumorprogressie inhibeert of dat het normale KIT betrokken is in de overleving van de cMCT (Hahn et al., 2008). Neveneffecten van mastinib zijn diarree, braken, oedeem en neutropenie (Hahn et al., 2008).

London et al. (2009) toonden aan dat er een verband is tussen de aanwezigheid van KIT-mutatie en de afwezigheid van metastasen naar de regionale lymfeknoop en de hogere objectieve respons na toediening van toceranib-fosfaat. Dit geneesmiddel inhibeert de tumorprogressie gemiddeld 12 tot 18 weken (London et al., 2009). Het zorgt voornamelijk voor gastro-intestinale toxiciteit met anorexie, gewichtsverlies, diarree, braken en melena. Daarnaast kunnen occasioneel een milde tot matige leukopenie en spierpijn optreden (London et al., 2009).

\section{Elekrochemotherapie}

Hierbij worden het lokaal injecteren van chemotherapeutica (cisplatine of bleomycine) en toediening van elektrische pulsen ter hoogte van de tumor gecombineerd om de opname van het geneesmiddel in de cellen te verhogen (Spugnini et al., 2011). Een volledige en een partiële reactie wordt opgemerkt na toepassing van deze behandelingstechniek (Spugnini et al., 2011). Het gebruik van elektrochemotherapie kan voordelig zijn op plaatsen waar chirurgische excisie moeilijk is zoals het perineum, de genitalieën en het hoofd (Spugnini et al., 2011).

\section{Cryotherapie}

Cryotherapie of -chirurgie wordt voornamelijk ingezet voor kleine nodulen $(<1 \mathrm{~cm})$, waarbij complete excisie moeilijk is omwille van hun lokalisatie (Krahwinkel, 1980). Deze therapie kan wel aanleiding geven tot mastceldegranulatie (Blackwood et al., 2012).

\section{Intraregionale therapie met gedeïonizeerd water}

Deze therapie kan als bijkomende behandeling worden gebruikt na incomplete chirurgische excisie (Grier et al., 2000). Uit een studie van Brocks et al.
(2008) bleek dat het inzetten van deze therapie niet resulteerde in een verlenging van de overlevingstijd noch op een daling van de kans op lokaal herval.

\section{Ondersteunende therapie}

Soms is het noodzakelijk om een ondersteunende therapie toe te dienen voor het inperken van systemische klachten veroorzaakt door histaminevrijstelling (Blackwood et al., 2012; London et al., 2013). Hiervoor worden H1- en H2-blokkers ingezet (London et al., 2013). Als H1-antagonist kan diphenhydramine (2-4 mg/kg PO BID) (Blackwood et al., 2012; London et al., 2013) of chlorpheniramine $(0,22$ tot $0,5 \mathrm{mg} / \mathrm{kg}$ TID) aangewend worden (London et al., 2013). Beide zorgen voor verminderde neveneffecten op de wondheling en de perifere vasculatuur (Blackwood et al., 2012). Voorbeelden van H2-antagonisten zijn cimetidine $(4 \mathrm{mg} / \mathrm{kg}$ PO TID), ranitidine (2 $\mathrm{mg} / \mathrm{kg}$ PO BID), famotidine $(0,5-1 \mathrm{mg} / \mathrm{kg}$ BID) of omeprazole $(0,5-1$ $\mathrm{mg} / \mathrm{kg}$ SID) (Blackwood et al., 2012; London et al., 2013).

De ondersteunende therapie wordt toegepast indien systemische klachten voorkomen en voor een chirurgische ingreep omwille van tumormanipulatie (London et al., 2012). In de aanwezigheid van gastroduodenale ulceraties kan bijkomend sucralfaat $(0,5-$ 1 g PO TID) toegediend (Blackwood et al., 2012; London et al. 2013).

\section{REFERENTIES}

Baker-Gabb M., Hunt G.B., France M.P. (2003). Soft tissue sarcomas and mast cell tumours in dogs; clinical behaviour and response to surgery. Australian Veterinary Journal 81, 732-738.

Berlato D., Rasotto R., Clifford C., Garett L., Hershey B., Intile J., Jones P., Bulman-Fleming J., Powell R., Kamstock D. Peauroi J., Pavuk A., Liptak J. (2017). Grading of canine cutaneous mast cell tumors. VCS/ACVP Oncology-Pathology Working Group, february 2017. http://vetcancersociety.org/vcs-members/ves-groups/ oncology-pathology-working-group/

Blackwood L., Murphy S., Buracco P., De Vos J.P., De Fornel-Thibaud P. , Hirschberger J., Kessler M., Pastor J., Ponce F., Savary-Bataille K., Argyle D.J. (2012). European consensus document on mast cell tumours in dogs and cats. Veterinary and Comparative Oncology 3, e1-e29.

Brocks B.A., Neyens I.J., Teske E., Kirpensteijn J. (2008). Hypotonic water as adjuvant therapy for incompletely resected canine mast cell tumours: a randomized, doubleblind, placebo-controlled study. Veterinary Surgery 37, 472-478.

Camus M.S., Priest H.L., Koehler J.W., Driskell E.A., Rakich P.M., Ilha M.R., Krimer P.M. (2016). Cytologic criteria for mast cell tumor grading in dogs with evaluation of clinical outcome. Veterinary Pathology 53, 11171123.

Dank G. (2016). Review of the treatment of canine cutaneous mast cell tumors. Israel Journal of Veterinary Medicine 71, 3-9. 
Davies D.R., Wyat K.M., Jardine J.E., Robertson I.D., Irwin P.J. (2004). Vinblastine and prednisolone as adjunctive therapy for canine cutaneous mast cell tumors. Journal of the American Animal Hospital Association 40, 124-130.

Davis B.J., Page R., Sannes P.L., Meuten D.J. (1992). Cutaneous mastocytosis in a dog. Veterinary Pathology 29, 363-365.

De Bosschere H., Deloose S. (2008). Mast cell leukemia in a dog. Vlaams Diergeneeskundig Tijdschrift 78, 49-52.

Dobson J.M., Scase T.J. (2007). Advances in the diagnosis and management of cutaneous mast cell tumours in dogs. Journal of Small Animal Practice 48, 424-431.

Donnelly L., Mullin C., Balko J., Goldschmidt M., Krick E., Hume C., Brown D.C., Sorenmo K. (2015). Evaluation of histological grade and histologically tumour-free margins as predictors of local recurrence in completely excised canine mast cell tumours. Veterinary and Comparative Oncology 13, 70-76.

Finora K., Leibman N.F., Fettman M.J., Powers B.E., Hackett T.A., Withrow S.J. (2006). Cytological comparison of fine-needle aspirates of liver and spleen of normal dogs and dogs with cutaneous mast cell tumours and an ultrasonographically normal appearing liver and spleen. Veterinary and Comparative Oncology 4, 178-183.

Gieger T.L., Théon A.P., Werner J.A., McEntee M.C., Rassnick K.M., DeCock H. (2003). Biologic behavior and prognostic factors for mast cell tumors of the canine muzzle: 24 cases (1990-2001). Journal of Veterinary Internal Medicine 17, 687-692.

Grier R.L., Di Guardo G. (2000). Deionised water and mast cell tumours. The Journal of Small Animal Practice 41, 368-371.

Hahn K.A., Oglivie G., Rusk T., Devauchelle P., Leblanc A., Legendre A., Powers B., Leventhal P.S., Kinet J.P., Palmerini F., Dubreuil P., Moussy A., Hermine O. (2008). Mastinib is safe and effective for the treatment of canine mast cell tumors. Journal of Veterinary Internal Medicine 22, 1301-1309.

Kiupel M. , Webster J.D. , Kaneene J.B., Miller R., Yuzbasiyan-Gurkan V. (2004). The use of KIT and tryptase expression patterns as prognostic tools for canine cutaneous mast cell tumors. Veterinary Pathology 41, 371-377.

Kiupel M. , Webster J.D., Bailey K.L. , Best S. , Delay J., Detrisac C.J., Fitzgerald S.D., Gamble D., Ginn P.E., Goldschmidt M.H., Hendrick M.J., Howerth E.W., Janovitz E.B., Langohr I., Lenz S.D., Lipscomb T.P., Miller M.A., Misdorp W., Moroff S., Mullaney T.P., Neyens I., O'Toole D., Ramos-Vara J., Scase T.J., Schulman F.Y., Sledge D. , Smedley R.C., Smith K., Snyder P.W. , Southorn E., Stedman N.L., Steficek B.A., Stromberg P.C., Valli V.E., Weisbrode S.E., Yager J., Heller J., Miller R. (2011). Proposal of a 2-tier histologic grading system for canine cutaneous mast cell tumors to accurately predict biological behavior. Veterinary Pathology 48, 147-155.

Kiupel M. (2017). Mast cell tumors. In: Meuten D.J. (editor). Tumors in Domestic Animals. Fifth Edition, p. 176200.

Krahwinkel D.J. Jr. (1980). Cryosurgical treatment of skin diseases. The veterinary Clinics of North America: Small Animal Practice 10, 787-801.

LaDue T., Price G.S., Dodge R., Page R.L., Thrall D.E. (1998). Radiation therapy for incompletely resected canine mast cell tumors. Veterinary Radiology Ultrasound $39,57-62$.
London C.A., Malpas P., Wood-Follis S.L., Boucher J.F., Rusk A.W., Rosenberg M.P., Henry C.J., Mitchener K.L., Klein M.K., Hintermeister J.G., Bergman P.J., Couto G.V., Mauldin G.N., Michels G.M. (2009). Multi-center, placebo-controlled, double-blind, randomized study of oral toceranib phosphate (SU11654), a receptor tyrosine kinase inhibitor, for the treatment of dogs with recurrent (either local or distant) mast cell tumor following surgical excision. Clinical Cancer Research 15, 3856-3865.

London C.A., Thamm D.H. (2013). Mast cell tumors. In: Withrow S.J., Vail D.M., Page R.L. (editors). Small Animal Clinical Oncology. Fifth edition, Elsevier, pp. 335355.

Marconato L. , Bettini G., Giacoboni C., Romanelli G., Zatelli A., Zini E. (2008). Clinicopathological features and outcome for dogs with mast cell tumors and bone marrow involvement. Journal of Veterinary Internal Medicine 22, 1001-1007.

McCaw D.L., Miller M.A., Ogilvie G.K., Withrow S.J., Brewer Jr. W.G., Klein M.K., Bell F.W., Anderson S.K. (1994). Response of canine mast cell tumors to treatment with oral prednisone. Journal of Veterinary Internal Medicine 8, 406-408.

Misdorp W. (2004) Mast cells and canine mast cell tumours. A review. Veterinary Quarterly 26, 156-169.

Mullins M., Dernell W.S., Withrow S.J., Ehrhart E.J., Thamm D.H. (2006). Evaluation of prognostic factors associated with outcome in dogs with multiple cutaneous mast cell tumors treated with surgery and without adjuvant treatment: 54 cases (1998-2004). Journal of the American Veterinary Medical Association 228, 91-95.

Murphy S., Sparkes A.H., Smith K.C., Blunden A.S., Brearley M.J. (2004). Relationships between the histological grade of cutaneous mast cell tumours in dogs, their survival and the efficacy of surgical resection. Veterinary Record 12, 743-746.

Murphy S., Sparkes A.H., Blunden A.S., Brearley M.J., Smith K.C. (2006). Effects of stage and number of tumours on prognosis of dogs with cutaneous mast cell tumours. Veterinary Record 158, 287-291.

O'Keefe D.A., Couto C.G. , Burke-Schwartz C., Jacobs R.M. (1987). Systemic mastocytosis in 16 dogs. Journal of Veterinary Internal Medicine 1, 75-80.

O'Keefe D.A. (1990) Canine mast cell tumors. Veterinary Clinic of North America: Small Animal Practice 20, 1105-1115.

Patnaik A.K., Ehler W.J., MacEwen E.G. (1984). Canine cutaneous mast cell tumor: morphologic grading and survival time in 83 dogs. Veterinary Pathology 21, 469-474.

Raskin R.E. (2010). Skin and subcutaneous tissues. In: Raskin R.E., Meyer D.J. (editors). Canine and Feline $C y$ tology: A Color Atlas and Interpretation Guide. Second edition, Saunders Elsevier, 67-69.

Reguera M.J., Rabanal R.M., Puigdemont A., Ferrer L. (2000). Canine mast cell tumors express stem cell factor receptor. The American Journal of Dermatopathology 22, 49-54.

Romansik E.M., Reilly C.M., Kass P.H., Moore P.F., London C.A. (2007). Mitotic Index is predictive for survival for canine cutaneous mast cell tumors. Veterinary Pathology 44, 335-341

Sabattini S., Scarpa F., Berlato D., Bettini G. (2015). Histologic grading of canine mast cell tumor: is 2 better than 3? Veterinary Pathology 52, 70-73.

Scase T.J., Miller J., Henley W., Smith K., Blunden A., 
Murphy S. (2006). Canine mast cell tumors: correlation of apoptosis and proliferation markers with prognosis. Journal of Veterinary Internal Medicine 20, 151-158.

Smith J., Kiupel M., Farrelly J., Cohen R., Omsted G., Kirpensteijn J., Brocks B., Post G. (2015). Veterinary and Comparative Oncology 14, 36-45.

Spugnini E.P., Vincenzi B., Citro G., Dotsinky I., Mudrov T., Baldi A. (2011). Evaluation of cisplatin as an electrochemotherapy agent for the treatment of incompletely excised mast cell tumors in dogs. Journal of Veterinary Internal Medicine 25, 407-411.

Stanclift R.M., Gilson S.D. (2008). Evaluation of neoadjuvant prednisolone administration and surgical excision in treatment of cutaneous mast cell tumors in dogs. Journal of the American Veterinary Medical Association 232, 5362.

Stefanello D., Valenti P. , Faverzani S., Bronzo V., Fiorbianco V., Pinto da Cunha N., Romussi S., Cantatore M., Caniatti M. (2009). Ultrasound-guided cytology of spleen and liver: a prognostic tool in canine cutaneous mast cell tumor. Journal of Veterinary Internal Medicine 23, 1051-1057.

Steffey M., Rassnick K.M., Porter B., Nijaa B.L. (2004).
Ureteral mast cell tumor in a dog. Journal of the American Animal Hospital Association 40, 82-85.

Teske E., Kirpensteijn J., Rutteman G.R. (2007). Het mastocytoom bij de hond. Tijdschrift voor Diergeneeskunde 132, 122-126.

Thompson J.J., Pearl D.L., Yager J.A. ,. Best S.J, Coomber B.L., Foster R.A. (2011). Canine subcutaneous mast cell tumor: characterization and prognostic indices. Veterinary Pathology 48, 156-168.

Vascellari M., Giantin M., Capello K., Carminato A., Morello E.M., Vercelli A., Granato A., Buracco P., Dacasto M., Mutinelli F. (2012). Expression of Ki67, BCL-2 en COX-2 in canine cutaneous mast cell tumors: association with grading and prognosis. Veterinary Pathology 50, 110-121.

Welle M.M., Bley C.R., Howard J., Rüfenacht S. (2008). Canine mast cell tumours: a review of the pathogenesis, clinical features, pathology and treatment. Journal Compilation 19, 321-339.

Zemke D., Yamini B., Yuzbasiyan-Gurkan V. (2002). Mutations in the juxtamembrane domain of c-kit are associated with higher grade mast cell tumors in dogs. Veterinary Pathology 39, 529-535.

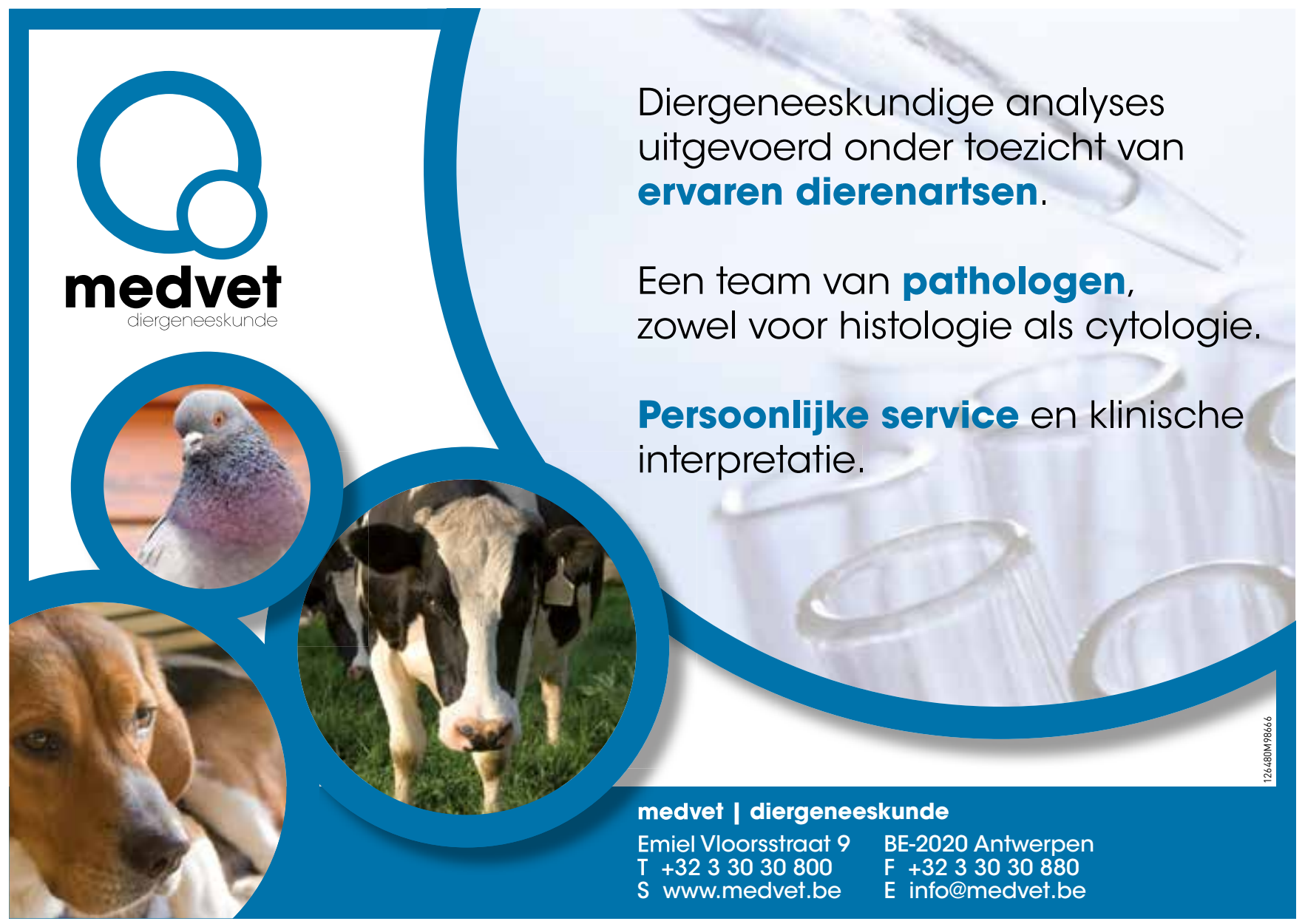

